\title{
A Novel Class of Neurons at the Trigeminal Subnucleus Interpolaris/Caudalis Transition Region Monitors Ocular Surface Fluid Status and Modulates Tear Production
}

\author{
Harumitsu Hirata, ${ }^{1}$ Keiichiro Okamoto, ${ }^{1}$ Akimasa Tashiro, ${ }^{1}$ and David A. Bereiter ${ }^{1,2}$ \\ Departments of ${ }^{1}$ Surgery and ${ }^{2}$ Neuroscience, Brown Medical School, Rhode Island Hospital, Providence, Rhode Island 02903
}

\begin{abstract}
Reflex tears are produced by many conditions, one of which is drying of the ocular surface. Although peripheral neural control of the lacrimal gland is well established, the afferent pathways and properties of central premotor neurons necessary for this reflex are not known. Male rats under barbiturate anesthesia were used to determine whether neurons at the ventral trigeminal subnucleus interpolaris-caudalis $(\mathrm{Vi} / \mathrm{Vc})$ transition or the trigeminal subnucleus caudalis-cervical cord $(\mathrm{Vc} / \mathrm{Cl})$ junction region in the lower brainstem were necessary for tears evoked by noxious chemical stimulation $\left(\mathrm{CO}_{2}\right.$ pulses) or drying of the ocular surface. Both the Vi/Vctransition and $\mathrm{Vc} / \mathrm{Cl}$ junction regions receive a dense direct projection from corneal nociceptors. Synaptic blockade of the $\mathrm{Vi} / \mathrm{Vc}$ transition, but not the $\mathrm{Vc} / \mathrm{C} 1$ junction, by the $\mathrm{GABA}_{\mathrm{A}}$ receptor agonist muscimol inhibited $\mathrm{CO}_{2}$-evoked tears. Glutamate excitation of the Vi/Vctransition, but not the $\mathrm{Vc} / \mathrm{Cl}$ junction, increased tear volume. Single units recorded at the $\mathrm{Vi} / \mathrm{Vc}$ transition, but not at the $\mathrm{Vc} / \mathrm{C} 1$ junction, were inhibited by wetting and excited by drying the ocular surface. Nearly all moisture-sensitive Vi/Vc units displayed an initial inhibitory phase to noxious concentrations of $\mathrm{CO}_{2}$ followed by delayed excitation and displayed an inhibitory surround receptive field from periorbital facial skin. Drying of the ocular surface produced many Fos-positive neurons at the Vi/Vctransition, but not at the $\mathrm{Vc} / \mathrm{Cl}$ junction. This is the first report of a unique class of moisture-sensitive neurons that exist only at the ventral $\mathrm{Vi} / \mathrm{Vc}$ transition, and not at more caudal portions of $\mathrm{Vc}$, that may underlie fluid homeostasis of the ocular surface.
\end{abstract}

Key words: cornea; dry eye; lacrimation; nociception; ocular irritation; spinal trigeminal nucleus

\section{Introduction}

The integrity of the ocular surface (i.e., cornea and conjunctiva) is essential for normal vision and depends on adequate formation of the tear film. The resting rate of tear production is thought to be driven by a reflex circuit consisting of afferent signals coming from the ocular surface, a relay to the superior salivatory nucleus (SSN) in the brainstem, and efferent outflow to autonomic ganglia and then to the lacrimal and meibomian glands (Stern et al., 1998; Mathers, 2000; Pflugfelder et al., 2000). Despite considerable progress in defining the peripheral neural mechanisms that directly influence lacrimal gland secretion (Walcott, 1998), no studies have determined the location or properties of central neurons that respond to acute changes in moisture status of the ocular surface and project to the SSN, i.e., the afferent limb of this reflex arc, the so-called premotor neurons. The ocular surface is supplied mainly by trigeminal ganglion neurons (Marfurt et al., 1989) that, in turn, send fibers centrally to terminate in the tri-

\footnotetext{
Received Feb. 3, 2004; revised March 18, 2004; accepted March 18, 2004.

This study was supported in part by a grant from the National Institute of Neurological Diseases and Stroke (NS26137). We thank Dominique F. Bereiter and Jessica Cioffi for expert technical assistance and Drs. James Hu (University of Toronto) and lan Meng (University of New England) for helpful comments in preparing this manuscript.

Correspondence should be addressed to Dr. David A. Bereiter, Brown Medical School, Rhode Island Hospital, Departments of Surgery and Neuroscience, 222 Nursing Arts Building, Providence, RI 02903-4970. E-mail: david_bereiter@brown.edu.

DOI:10.1523/JNEUROSCI.0381-04.2004

Copyright $\odot 2004$ Society for Neuroscience $\quad 0270-6474 / 04 / 244224-09 \$ 15.00 / 0$
}

geminal brainstem complex (Marfurt, 1981; Panneton and Burton, 1981; Marfurt and del Toro, 1987; Gong et al., 2003). The lower portion of the trigeminal brainstem complex, the spinal trigeminal nucleus (Vsp), consists of three subnuclei-oralis $(\mathrm{Vo})$, interpolaris $(\mathrm{Vi})$, and caudalis $(\mathrm{Vc})$, from rostral to caudal, respectively-and receives somatic sensory information from all structures of the head and oral cavity. Studies concerned with central neural pathways of trigeminal pain have emphasized the role of Vc because this subnucleus shares many properties with the spinal dorsal horn (Dubner and Bennett, 1983; Sessle, 2000). Indeed, neurons in caudal portions of Vc encode the intensity of corneal stimulation and are inhibited by opioid analgesic drugs, consistent with a role in pain processing (Meng et al., 1997, 1998; Hirata et al., 1999, 2000). A distinctive feature of the trigeminal system, however, is that craniofacial structures, including the ocular surface, are represented at more than one level of the Vsp. This has led to the proposal that different subnuclei of the Vsp serve different aspects of trigeminal function (Renehan and Jacquin, 1993; Bereiter et al., 2000; Sessle, 2000). In rodents the ocular surface is represented mainly at two spatially distinct regions: the trigeminal subnucleus interpolaris-caudalis $(\mathrm{Vi} / \mathrm{Vc})$ transition and subnucleus caudalis-upper cervical spinal cord (Vc/C1) junction regions (Marfurt and del Toro, 1987; Lu et al., 1993; Strassman and Vos, 1993; Meng and Bereiter, 1996; Gong et al., 2003). The present study measured tear volume and recorded single unit activity to test the hypothesis that the rostral $\mathrm{Vi} / \mathrm{Vc}$ 


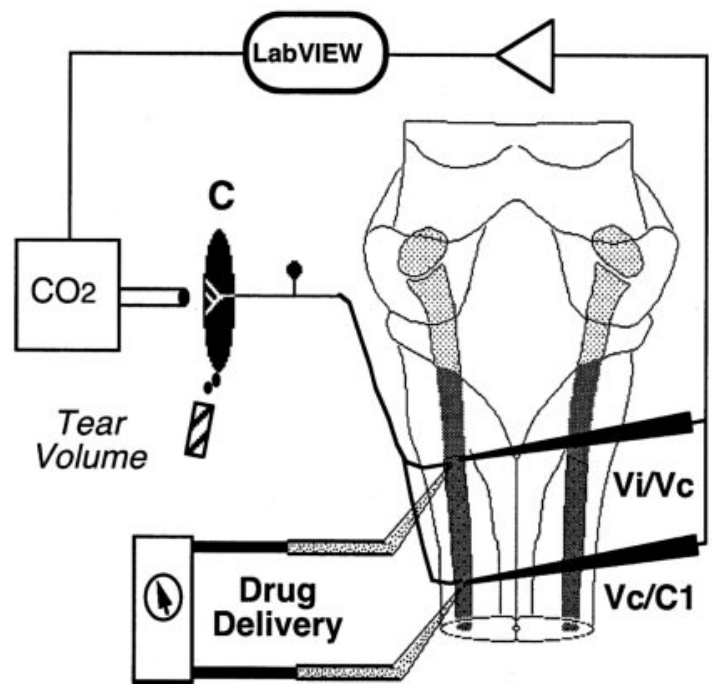

Figure 1. Experimental setup to measure tear volume and single-unit activity in response to ocular stimulation. The timing and concentration of $\mathrm{CO}_{2}$ stimulus pulses as well as data collection were controlled by a computer and LabVIEW software. Drugs were delivered by pressure injection monitored visually by the movement of the meniscus. C, Cornea; $\mathrm{Vc} / \mathrm{C} 1$, trigeminal subnucleus caudalis- cervical spinal cord junction region; $\mathrm{Vi} / \mathrm{Vc}$, trigeminal subnucleus interpolaris-caudalis transition region.

transition and caudal $\mathrm{Vc} / \mathrm{C} 1$ junction regions contribute differentially to the control of fluid homeostasis of the ocular surface.

\section{Materials and Methods}

The protocols were approved by the Institutional Animal Care and Use Committee of Rhode Island Hospital and conformed to the established guidelines set by The National Institutes of Health Guide for the Care and Use of Laboratory Animals (PHS Law 99-158, revised 2002).

\section{Surgical preparation}

Male rats (270-440 gm; Sprague Dawley, Harlan) were anesthetized initially with pentobarbital sodium $(70 \mathrm{mg} / \mathrm{kg}$, i.p.) before surgery. The left femoral artery (blood pressure monitor) and jugular vein (anesthesia and drug infusions) were catheterized, and after tracheotomy, animals were artificially respired with oxygen-enriched room air. Anesthesia was maintained by a continuous infusion of methohexital sodium (35-40 $\mathrm{mg} \cdot \mathrm{kg}^{-1} \cdot \mathrm{hr}^{-1}$ ) and switched to a mixture of methohexital sodium $\left(26-40 \mathrm{mg} \cdot \mathrm{kg}^{-1} \cdot \mathrm{hr}^{-1}\right)$ and the paralytic agent, gallamine triethiodide $\left(14-32 \mathrm{mg} \cdot \mathrm{kg}^{-1} \cdot \mathrm{hr}^{-1}\right)$, after completion of all surgical procedures and just before the recording session. The animal was placed in a stereotaxic frame, and portions of the occipital bone and $\mathrm{C} 1$ vertebra were removed to expose the dorsal surface of the medulla. The brainstem surface was covered with warm mineral oil. Expiratory end-tidal $\mathrm{CO}_{2}$ was monitored continuously and kept at $4-5 \%$ by adjusting tidal volume. Mean arterial pressure (MAP) remained above $100 \mathrm{mmHg}$ throughout the experiment. Body temperature was maintained at $38^{\circ} \mathrm{C}$ with a heating blanket and thermal probe.

\section{Electrophysiology recording techniques}

Single neurons were recorded at the rostral $\mathrm{Vi} / \mathrm{Vc}$ transition and laminas $\mathrm{I}-\mathrm{II}$ at the caudal $\mathrm{Vc} / \mathrm{C} 1$ junction region extracellularly using tungsten electrodes (9-15 M $\Omega$; FHC, Bowdoinham, ME) as described previously (Meng et al., 1997; Hirata et al., 1999, 2003) (Fig. 1). Light mechanical (fine camel-hair brush) stimulation of the corneal surface was used to search for responsive neurons. Unit activity was amplified, displayed on a digital oscilloscope to monitor spike shape and amplitude, and passed through a window discriminator. Discriminated neural spikes, MAP, and a marker for $\mathrm{CO}_{2}$ stimulus pulses were acquired and displayed online with an Apple computer (G3) through a DAQ interface board using LabVIEW software (National Instruments, Austin, TX). Data were also recorded on a four-channel DAT/SCSI-based acquisition system (Cygnus Technology) for further off-line analyses.

Units were tested for several general response properties and then for A- and C-fiber type corneal input (electrical stimuli applied from a bipolar electrode, $2 \mathrm{~mm}$ separation, mounted on the ear bar). Electrical evoked responses occurring after $30 \mathrm{msec}$ were assumed to indicate C-fiber input (Hu, 1990; Meng et al., 1997). Convergent cutaneous receptive field (RF) properties were determined by applying innocuous mechanical stimulation and then noxious pinch and deep pressure to the ipsilateral face. Corneal units with an excitatory convergent cutaneous RF were classified as either low-threshold mechanoreceptive (LTM), wide dynamic range (WDR), or nociceptive-specific (NS) units. In addition, many corneal units at the $\mathrm{Vi} / \mathrm{Vc}$ transition were classified as "complex," defined by an inhibitory convergent cutaneous RF, which was contiguous with the cornea-conjunctiva border and occurred alone or in addition to an excitatory cutaneous RF. The inhibitory RF of complex units was mapped by light pinch stimulation with a small forceps and often included the ipsilateral intranasal mucosa. Neurons with no apparent cutaneous RF were classified as cornea only (CO) units. Although the term "corneal unit" is used throughout the text, no effort was made to distinguish between units responsive to corneal stimulation alone and those responsive to corneal plus conjunctival stimulation.

In some cases an electrode array was positioned at the SSN-facial motor nucleus region (SSN/VII) (Toth et al., 1999) to test for efferent projections. The array was angled rostral $2^{\circ}$ off vertical at the following coordinates: $4 \mathrm{~mm}$ caudal to $\lambda, 2 \mathrm{~mm}$ lateral, and $5-7 \mathrm{~mm}$ ventral to the cerebellar surface. Tests for antidromic activation were done after all other testing was complete to avoid possible persistent effects from highintensity and high-frequency stimulation. Stimuli were presented from an array of two (1-2 $\mathrm{mm}$ rostrocaudal separation) concentric bipolar stimulating electrodes (SNE-100, Rhodes Medical Instruments). Antidromically evoked spikes were driven at a constant latency $(<0.1 \mathrm{msec}$ jitter), followed by high frequency ( $0.1 \mathrm{msec}$ pulse, $200-300 \mathrm{~Hz}, 20 \mathrm{msec}$ train duration), and were collided with orthodromically driven spikes occurring within a critical time window (Lipski, 1981). A stimulus intensity of $500 \mu \mathrm{A}$ was defined as the maximum allowable current for specific activation. Sites of lowest current for antidromic activation were marked electrolytically $(30 \mu \mathrm{A}, 30 \mathrm{sec})$.

\section{Corneal stimulation by carbon dioxide}

The general setup for the experimental design is shown in Figure 1, and a detailed description of the delivery of $\mathrm{CO}_{2}$ pulses to the corneal surface has been reported previously (Hirata et al., 2000). Briefly, variable concentrations $(0-95 \%)$ of $\mathrm{CO}_{2}$ gas were obtained by mixing the outflow from tanks of $100 \% \mathrm{CO}_{2}$ and air through a proportional gas mixer as monitored from the bleeder valve output by an infrared detector (CapStar 100, CWE, Ardmore, PA). Humidified $\mathrm{CO}_{2}$ gas mixtures were delivered at a constant flow rate to the left cornea. The timing and duration of $\mathrm{CO}_{2}$ pulses ( $40 \mathrm{sec}$ duration, minimum of 15 min between pulses) were computer-controlled by LabVIEW software. In most experiments only the responses to $0 \%$ (air) and $80 \% \mathrm{CO}_{2}$ pulses were compared. In some cases, however, a range of $\mathrm{CO}_{2}$ concentrations $(0,30,60,80$, and $95 \%$ ) was used to confirm that the threshold and slope of the neural stimulus-response curves were similar to those reported previously (Hirata et al., 1999). The cornea was kept moist with a pH-balanced artificial tear fluid during surgery and the interstimulus intervals throughout the experiment.

\section{Drug administration}

Drugs were injected into the $\mathrm{Vi} / \mathrm{Vc}$ transition and $\mathrm{Vc} / \mathrm{C} 1$ junction regions using a single- or dual-barrel thick-walled micropipette $(40-80 \mu \mathrm{m}$, outer diameter). The selective $\mathrm{GABA}_{\mathrm{A}}$ receptor agonist muscimol hydrobromide (Sigma, St. Louis, MO; $0.5 \mathrm{~mm}, \mathrm{pH}$ 6.7) or the $\mathrm{GABA}_{\mathrm{A}}$ antagonist bicuculline methiodide (BMI) (Sigma; $0.5 \mathrm{~mm}, \mathrm{pH}$ 6.1) was delivered by pressure microinjection (Neuro-Phore, Medical Systems, Greenvale, $\mathrm{NY}$ ) in a volume of $300 \mathrm{nl}$ over $5 \mathrm{~min}$. Microinjections of L-glutamate ( 10 $\mathrm{mm}, \mathrm{pH} 6.8,300 \mathrm{nl}$ ) were made over 2 min. Drugs were dissolved in artificial CSF containing (in $\mathrm{mm}$ ): $150 \mathrm{NaCl}, 2.6 \mathrm{KCl}, 1.3 \mathrm{CaCl}_{2}, 1.8$ $\mathrm{MgCl}_{2}$, and mixed with a $10 \%$ solution of Evan's Blue dye to visualize the 
location of injection. In experiments in which unit activity was recorded and muscimol injected, the drug was delivered from a separate glass micropipette angled stereotaxically to a target position $0.5-0.8 \mathrm{~mm}$ from the recording electrode. This proximity was confirmed histologically after the experiment from the deposition of Evan's Blue dye and a lesion at the recording site.

\section{Experimental design}

Tear volume. Tear volume was measured using three experimental designs in separate preparations. In each experiment, tear volume was estimated by the change in weight of a filter paper $(\sim 5 \times 8 \mathrm{~mm})$ in contact with the cornea-conjunctiva for $2 \mathrm{~min}$ per sample. The filter paper was positioned at the inferior-lateral edge of the cornea-conjunctiva interface, which allowed tear volume to be determined while $\mathrm{CO}_{2}$ pulses were applied to the center of the cornea. First, tears were evoked by a graded series of $\mathrm{CO}_{2}$ pulses ( $40 \mathrm{sec}$ duration) and measured at the start of the experiment. Each filter paper was weighed and then placed at the corneaconjunctiva border $1 \mathrm{~min}$ before and removed $1 \mathrm{~min}$ after stimulus onset. The cornea was kept moist with artificial tears during the interstimulus intervals ( $15 \mathrm{~min}$ ), and excess fluid was removed just before placement of the filter paper for subsequent samples. Second, the effect of local synaptic blockade of the rostral $\mathrm{Vi} / \mathrm{Vc}$ transition or caudal $\mathrm{Vc} / \mathrm{C} 1$ junction regions on tears evoked by $80 \% \mathrm{CO}_{2}$ pulses was assessed. Local synaptic blockade by muscimol injection began $4 \mathrm{~min}$ before presentation of the $80 \% \mathrm{CO}_{2}$ test pulse. Subsequent 2 min samples were collected at 5, 20, and $35 \mathrm{~min}$ after muscimol, and then the selective $\mathrm{GABA}_{\mathrm{A}}$ receptor antagonist BMI was injected through the second barrel of the dual pipette 4 min before presentation of the last $80 \% \mathrm{CO}_{2}$ test pulse. In the third design, microinjections of L-glutamate $(10 \mathrm{~mm}, 300 \mathrm{nl})$ were made into the rostral $\mathrm{Vi} / \mathrm{Vc}$ transition or caudal $\mathrm{Vc} / \mathrm{C} 1$ junction regions to determine the effect of local synaptic excitation on tear formation. Tear volume samples were taken 2 min before glutamate, for 2 min beginning at the onset of injection and from 3 to $5 \mathrm{~min}$ after injection. Filter paper weight was measured accurately to $\pm 0.1 \mathrm{mg}$ on an electronic balance. In preliminary measurements it was determined that deposition of $1 \mu \mathrm{l}$ of artificial tear fluid was equal to a $1.1 \mathrm{mg}$ change in filter paper weight.

Corneal unit activity. One corneal unit was studied in each experiment and recorded at either the $\mathrm{Vi} / \mathrm{Vc}$ transition or $\mathrm{Vc} / \mathrm{C} 1$ junction region. After the general RF properties were determined as described above, excess tears were removed by gently placing a small piece of filter paper at the lower lateral cornea-conjunctiva junction, and then units were tested for possible $\mathrm{CO}_{2}$ responsiveness with a pulse of $0 \% \mathrm{CO}_{2}$ at a flow rate that had a minimal effect on spontaneous activity followed by two pulses of $80 \% \mathrm{CO}_{2}$ presented at 15 min intervals. Generally, only $\mathrm{CO}_{2}$-responsive units were studied in detail, whereas units not responsive to $\mathrm{CO}_{2}$ were classified as "mechanical only" and excluded from further analyses. Units displaying at least a $50 \%$ increase in activity above background to $80 \%$ $\mathrm{CO}_{2}$ were tested further for responses to moisture and drying of the corneal surface. Excess spontaneous tears were removed, and then background unit activity was recorded continuously for $5 \mathrm{~min}$ before and after application of $20 \mu \mathrm{l}$ of artificial tears to the corneal surface and after tear removal. All additional testing such as for $\mathrm{CO}_{2}$ intensity-response relationships or sensitivity to drugs followed the initial collection of results for moisture and drying. In cases during which the effects of GABAergic drugs were tested, drug injection began 6 min after the second control $80 \% \mathrm{CO}_{2}$ pulse and continued for $5 \mathrm{~min}$. Then $4 \mathrm{~min}$ later (i.e., $15 \mathrm{~min}$ after the previous $80 \% \mathrm{CO}_{2}$ pulse), another series of test pulses was presented followed by additional pulses of $80 \% \mathrm{CO}_{2}$ every 15 min for $1 \mathrm{hr}$.

\section{C-fos immunocytochemistry}

A separate group of male rats was used to determine whether acute drying ( $2 \mathrm{hr}$ duration) of the ocular surface was sufficient to cause widespread excitation at different levels of the trigeminal brainstem complex in regions not assessed by electrophysiology. Under barbiturate anesthesia (pentobarbital sodium, $65 \mathrm{mg} / \mathrm{kg}$ ), the upper and lower eyelids of the left eye were retracted with small adhesive strips, and spontaneous tears were removed by filter paper placed at the lateral edge of the ocular surface throughout the $2 \mathrm{hr}$ survival period. Care was taken to avoid directly touching the ocular surface. Control animals were anesthetized, and the eyelids were allowed to close and tears to accumulate. After $2 \mathrm{hr}$, animals were perfused (fixative: $4 \%$ paraformaldehyde, $0.1 \mathrm{~m}$ phosphate buffer, $\mathrm{pH}$ 7.3) and postfixed overnight. Transverse brainstem sections were cut on a vibratome at $50 \mu \mathrm{m}$ and incubated successively in 5\% donkey serum (30 min), affinity-purified rabbit polyclonal anti-Fos antibody (Ab) (Ab-5, Oncogene Science; $1: 15,000,40 \mathrm{hr}$ at $4^{\circ} \mathrm{C}$ ), biotinylated donkey anti-rabbit secondary Ab (1:300, 105 min; Chemicon, Temecula, CA), and avidin-biotin-peroxidase complex (60 min; Vector Laboratories, Burlingame, CA). Fos-like immunoreactivity (Fos-LI) was visualized after 2-4 min incubation in activated nickel-cobalt-diaminobenzidine solution. Fos-LI was observed under bright-field illumination and distinguished as a homogenous gray-black precipitate restricted to cell nuclei. Controls for Fos Ab specificity were processed as above except that the primary antiserum was omitted.

Brainstem sections were categorized according to their approximate rostrocaudal location at $500 \mu \mathrm{m}$ intervals from $2 \mathrm{~mm}$ rostral to $7 \mathrm{~mm}$ caudal to the obex. The obex is a surface landmark defined by the caudal end of the fourth ventricle $\sim 500 \mu \mathrm{m}$ rostral to the most caudal tip of Vi (Yoshida et al., 1991). Sixty to 70 sections per animal were counted at $100 \times$ magnification without previous knowledge of the experimental treatment. The number of Fos-positive neurons per section was compared across treatments at different rostrocaudal levels of the Vsp by two-way ANOVA. Individual comparisons were made by the NewmanKeuls test after ANOVA (Winer, 1971).

\section{Data analysis}

Neural recording data were acquired and displayed by LabVIEW as peristimulus time histograms of spikes per $1 \mathrm{sec}$ bins, exported to a spreadsheet, and analyzed off-line. The responses to moisture and drying of the cornea-conjunctiva surface were determined from the average spontaneous activity rate (spikes per bin) sampled $30 \mathrm{sec}$ immediately before and after application of artificial tears to the cornea (wet state) and then after an additional $10 \mathrm{~min}, 30 \mathrm{sec}$ before and after tears were removed (dry state). As described previously (Hirata et al., 1999), two main classes of corneal units at the $\mathrm{Vi} / \mathrm{Vc}$ transition region were activated by $\mathrm{CO}_{2}$ pulses. Type I units displayed a late excitatory phase (latency $=7-22 \mathrm{sec}$ ) that was proportional to $\mathrm{CO}_{2}$ concentration. Type II units displayed an early inhibitory phase (latency $<10 \mathrm{sec}$ ) in addition to the late excitatory phase. Examples of type I and type II unit responses to $\mathrm{CO}_{2}$ stimulation are shown in Figure 5. To confirm the early-onset inhibitory period of type II units, only neurons with a background discharge of $>1 \mathrm{~Hz}$ were included for further analyses. Accordingly, the average background discharge rate for $\mathrm{Vi} / \mathrm{Vc}$ units in this study was somewhat elevated compared with previous reports in which $\sim 30 \%$ of $\mathrm{Vi} / \mathrm{Vc}$ units had a low $(<$ $0.5 \mathrm{~Hz}$ ) rate (Hirata et al., 1999). All $\mathrm{CO}_{2}$-responsive units recorded in laminas I-II at the caudal $\mathrm{Vc} / \mathrm{C} 1$ junction region displayed a type I-like response pattern consisting of a single late excitatory response proportional to $\mathrm{CO}_{2}$ concentration. Excitatory responses to $\mathrm{CO}_{2}$ pulses for type $\mathrm{I}$ and type II units were quantified by calculating the total response magnitude (total $R_{\text {mag }}$ ) of the late excitatory component. The total $R_{\text {mag }}$ for a given stimulus was defined as the cumulative sum of spikes for those contiguous bins in which the spike count exceeded the mean +2 SD of the background activity. The total $R_{\text {mag }}$ was calculated for each $\mathrm{CO}_{2}$ stimulus period and can be thought of as equivalent to the "area under the curve." Units classified as type II displayed an initial inhibitory phase within $10 \mathrm{sec}$ after the onset of $80 \% \mathrm{CO}_{2}$ stimulation that was at least $50 \%$ below background activity. The maximum initial inhibitory response for type II units was defined as the maximum percentage decrease from background activity averaged over five consecutive bins after the onset of $80 \% \mathrm{CO}_{2}$ pulses. Similarly, a maximum inhibitory response for type II units to wetting the ocular surface was defined as the maximum percentage decrease from background activity averaged over five consecutive bins after the application of artificial tear fluid. Many type II units were classified further as complex cells, i.e., having a convergent inhibitory cutaneous RF. Inhibitory RF areas of complex units were mapped onto standardized drawings of the rat face, digitized, and quantified by a planimetric method using NIH Image software (v. 1.61). Unit activity recorded before and after wetting and drying the cornea, total $R_{\text {mag }}$, initial 

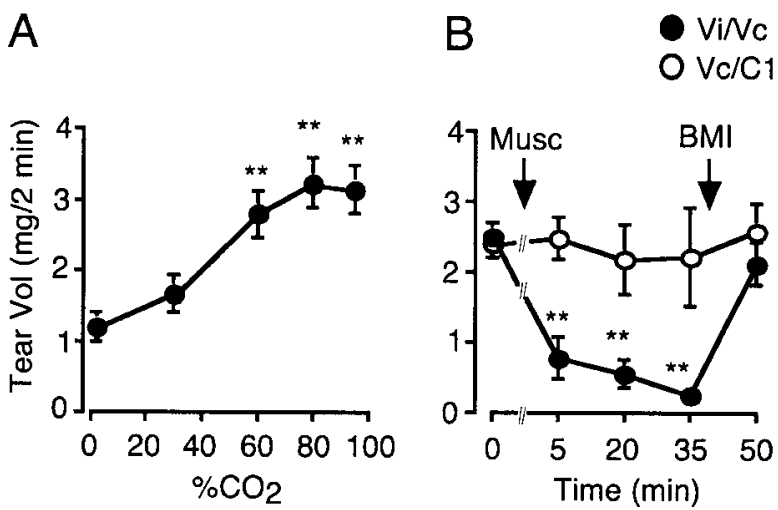

Figure 2. $A$, Graded concentrations of $\mathrm{CO}_{2}$ pulses applied to the ocular surface increased tear volume. Tear volume was increased above spontaneous baseline levels after $60 \% \mathrm{CO}_{2} \cdot{ }^{* *} p<$ 0.01 versus $0 \% \mathrm{CO}_{2}$ stimulus; $n=19 . B$, Microinjection of the selective $\mathrm{GABA}_{\mathrm{A}}$ receptor agonist muscimol (Musc) into the rostral Vi/Vc transition region inhibited $\mathrm{CO}_{2}$-evoked tear formation, whereas injection into the caudal $\mathrm{Vc} / \mathrm{C} 1$ junction region had no effect. Muscimol-induced inhibition of $\mathrm{CO}_{2}$-evoked tear formation was reversed after injection of the selective $\mathrm{GABA}_{\mathrm{A}}$ receptor antagonist bicuculline methiodide $(0.5 \mathrm{~mm})$. Muscimol $(0.5 \mathrm{~mm})$ and BMI were injected in $300 \mathrm{nl}$ over 5 min. ${ }^{* *} p<0.01$ versus $0 \% \mathrm{CO}_{2}$ stimulus; $\mathrm{Vi} / \mathrm{Vc}, n=11 ; \mathrm{Vc} / \mathrm{C} 1, n=7$. Test stimuli of $80 \% \mathrm{CO}_{2}$ were given every $15 \mathrm{~min}$.

inhibitory phase (for type II units only) to $\mathrm{CO}_{2}$ stimulation, and inhibitory RF areas of complex units were assessed statistically by ANOVA corrected for repeated measures (Winer, 1971) and individual comparisons by Newman-Keuls. Spearman rank-order analysis determined whether changes in inhibitory phase magnitude to $\mathrm{CO}_{2}$ and wetting of the cornea were correlated. Changes in tear volume and mean arterial pressure to $\mathrm{CO}_{2}$ stimulation were assessed by ANOVA corrected for repeated measures.

\section{Histology}

At the end of the experiment, the animal was given a bolus of pentobarbital sodium $(60 \mathrm{mg} / \mathrm{kg}$, i.v. $)$ and perfused through the heart with saline followed by $10 \%$ formalin plus saturated potassium ferrocyanide. Brainstem sections were cut at $40 \mu \mathrm{m}$ on a freezing microtome and stained with cresyl violet. Recording sites at the rostral Vi/Vc transition and caudal $\mathrm{Vc} / \mathrm{C} 1$ junction regions were marked electrolytically $(5 \mu \mathrm{A}, 10$ $\mathrm{sec})$. Antidromic stimulation sites in SSN/VII were reconstructed and drawn on a standardized series of brain outlines adapted from the atlas of Paxinos and Watson (1997). Microinjection sites for muscimol, BMI, and glutamate were identified from the deposit of Evan's Blue dye.

\section{Results}

Tear volume

Tear volume was low $(0.3 \pm 0.1 \mathrm{mg} / 2 \mathrm{~min} ; n=15)$ in the absence of overt stimulation; however, pulses of room air $\left(0 \% \mathrm{CO}_{2}\right)$ were sufficient to cause a small but significant increase $(1.2 \pm 0.2 \mathrm{mg} / 2$ min; $n=19)$ compared with the unstimulated condition $(p<$ $0.005 ; F=12.6 ; \mathrm{df}=1,30)$. Increasing concentrations of $\mathrm{CO}_{2}$ gas applied to the ocular surface evoked progressive increases in tear volume as seen in Figure $2 \mathrm{~A}$. After $60 \% \mathrm{CO}_{2}$, tear volume was increased significantly above the response to $0 \% \mathrm{CO}_{2}$, with a maximum increase observed after $80 \% \mathrm{CO}_{2}$. This was a consistent finding because at least a $65 \%$ increase in tear volume occurred after stimulation by $80 \% \mathrm{CO}_{2}$ pulses in 16 of 19 experiments. Stimulation with $80 \% \mathrm{CO}_{2}$ did not cause a significant change in tear volume produced by the contralateral eye $(n=3$; change in volume $<0.3 \mathrm{mg}$ ). Mean arterial pressure increased transiently after $80 \% \mathrm{CO}_{2}(+2.7 \pm 0.6 \mathrm{mmHg} ; p<0.01)$ but not after lower concentrations of $\mathrm{CO}_{2}$.

The selective $\mathrm{GABA}_{\mathrm{A}}$ receptor agonist muscimol was injected into the rostral $\mathrm{Vi} / \mathrm{Vc}$ transition or caudal $\mathrm{Vc} / \mathrm{C} 1$ junction region to determine whether local synaptic activity in either region was

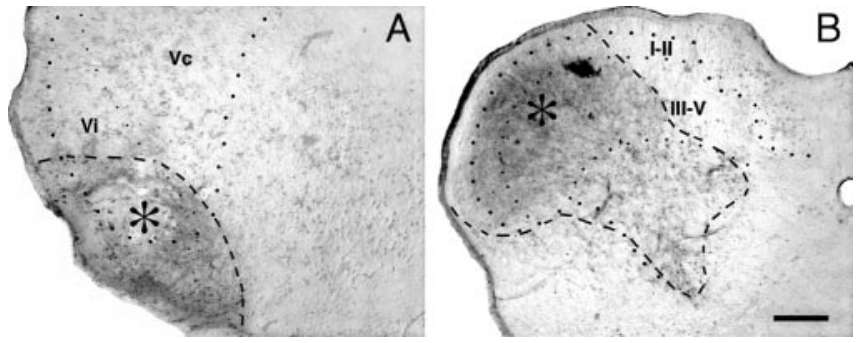

Figure 3. Examples of muscimol injection sites at the rostral Vi/Vctransition $(A)$ and caudal $\mathrm{Vc} / \mathrm{C} 1$ junction $(B)$ regions as identified by the deposit of Evan's Blue dye. Asterisk indicates center of injection; dashed lines indicate the limits of visible dye spread. Dotted lines indicate approximate borders of the $\mathrm{Vi} / \mathrm{Vc}$ and laminar portion of the medullary dorsal horn in $A$ and $B$, respectively. Scale bar, $300 \mu \mathrm{m}$.

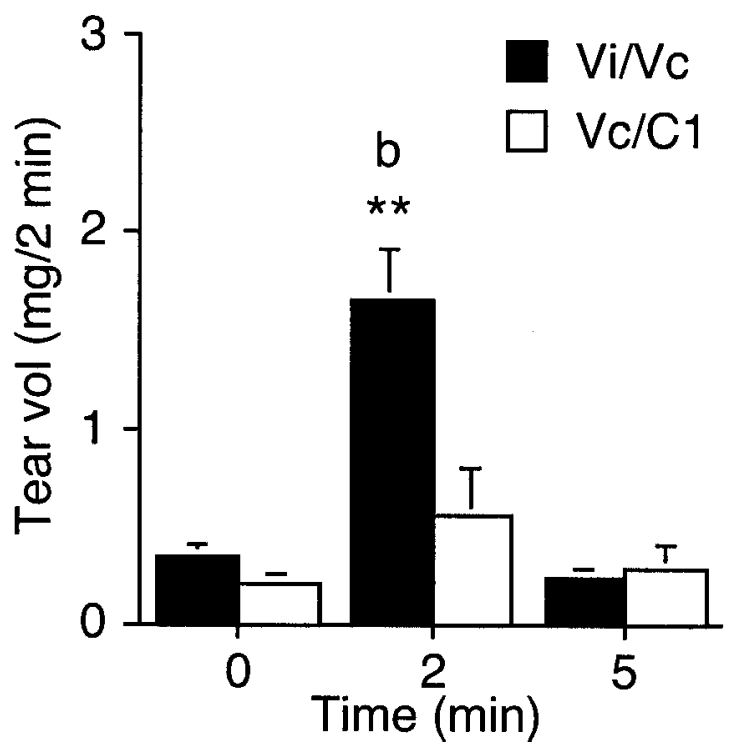

Figure 4. Microinjection of glutamate $(10 \mathrm{~mm})$ into the rostral Vi/Vc transition but not the caudal $\mathrm{Vc} / \mathrm{C} 1$ junction region caused a prompt increase in tear volume. Tear volume was measured over $2 \mathrm{~min}$ before injection, during the first $2 \mathrm{~min}$ after the start of injection (Post 1), and 3-5 min after injection (Post 2). Sample size: $\mathrm{Vi} / \mathrm{Vc}=18 ; \mathrm{Vc} / \mathrm{C} 1=11 .{ }^{* *} p<0.01$ versus prestimulus tear volume; $b=p<0.01$, Vi/Vc versus $\mathrm{Vc} / \mathrm{C} 1$ sites.

necessary for $\mathrm{CO}_{2}$-evoked tear formation. Muscimol injection into the $\mathrm{Vi} / \mathrm{Vc}$ transition region significantly $(p<0.01)$ reduced tear volume evoked by $80 \% \mathrm{CO}_{2}$ pulses, an effect reversed by injection of the selective $\mathrm{GABA}_{\mathrm{A}}$ receptor antagonist (Fig. $2 \mathrm{~B}$ ). In contrast, muscimol injection into the caudal $\mathrm{Vc} / \mathrm{C} 1$ junction region did not inhibit $\mathrm{CO}_{2}$-evoked tear formation. Examples of injection sites in the rostral $\mathrm{Vi} / \mathrm{Vc}$ transition and caudal $\mathrm{Vc} / \mathrm{C} 1$ junction regions are shown in Figure 3. Note that at the $\mathrm{Vi} / \mathrm{Vc}$ transition (Fig. $3 A$ ) dye was restricted to the ventral portion of the nucleus, whereas at the $\mathrm{Vc} / \mathrm{C} 1$ junction region dye spread throughout the lateral dorsal horn (Fig. $3 B$ ).

Glutamate was injected into the rostral Vi/Vc transition or $\mathrm{Vc} / \mathrm{C} 1$ junction region to determine whether local excitation of either region altered tear production. As seen in Figure 4, glutamate excitation of the $\mathrm{Vi} / \mathrm{Vc}$ transition, but not the $\mathrm{Vc} / \mathrm{C} 1$ junction region, significantly increased tear volume $(F=34.1$; $\mathrm{df}=$ $2,54 ; p<0.001)$.

\section{Corneal unit activity}

General properties

A total of 111 neurons were recorded at the $\mathrm{Vi} / \mathrm{Vc}$ transition region $(n=69)$ and in laminas $\mathrm{I}-\mathrm{II}$ at the $\mathrm{Vc} / \mathrm{C} 1$ junction region 
Table 1. Summary of cells and their classification tested for responsiveness to acute moisture and drying of the ocular surface

\begin{tabular}{|c|c|c|c|c|}
\hline \multirow[b]{2}{*}{ Recording site } & \multirow[b]{2}{*}{$\mathrm{CO}_{2}$ class } & \multirow{2}{*}{$\begin{array}{l}\text { Cutaneous RF } \\
\text { class }(n)\end{array}$} & \multicolumn{2}{|c|}{$\begin{array}{l}\text { Response to wet cornea } \\
(\Delta>50 \%)\end{array}$} \\
\hline & & & Inhibition & Excitation \\
\hline \multirow[t]{8}{*}{$\mathrm{Vi} / \mathrm{Vc}(n=69)$} & \multirow[t]{5}{*}{ Type I $(n=38)$} & $\mathrm{CO}(8)$ & $0 / 8$ & $0 / 8$ \\
\hline & & $\operatorname{LTM}(2)$ & $2 / 2$ & $0 / 2$ \\
\hline & & WDR (16) & $0 / 16$ & $0 / 16$ \\
\hline & & NS (4) & $0 / 4$ & $0 / 4$ \\
\hline & & Complex (8) & $1 / 8$ & $0 / 8$ \\
\hline & \multirow[t]{3}{*}{ Type II $(n=31)$} & $\operatorname{LTM}(2)$ & $2 / 2$ & $0 / 2$ \\
\hline & & NS (1) & $1 / 1$ & $0 / 1$ \\
\hline & & Complex (28) & $27 / 28$ & $0 / 28$ \\
\hline \multirow[t]{3}{*}{$\mathrm{Vc} / \mathrm{C1}(n=42)$} & \multirow[t]{3}{*}{ Type I $(n=42)$} & WDR (26) & $0 / 26$ & $1 / 26$ \\
\hline & & NS (15) & $0 / 15$ & $2 / 15$ \\
\hline & & Complex (1) & $0 / 1$ & $0 / 1$ \\
\hline
\end{tabular}

Numbers in parentheses indicate total per class. Complex, Inhibitory cutaneous receptive field. For definitions of cell classes, see Materials and Methods.
Type I, Unit 1-17-01

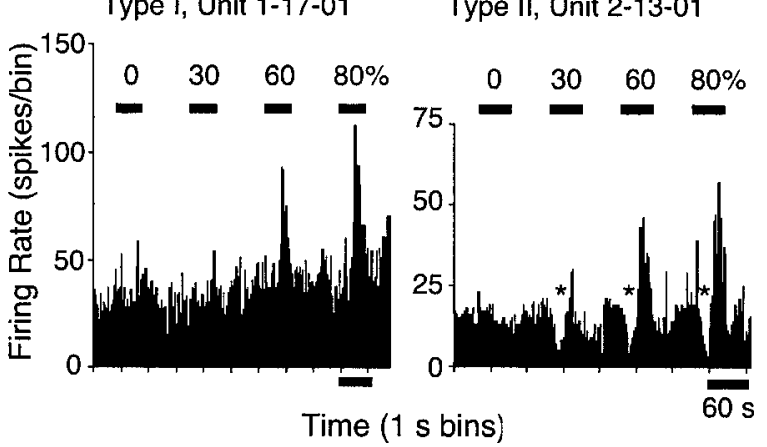

Figure 5. Examples of peristimulus time histograms of corneal units recorded at the rostral $\mathrm{Vi} / \mathrm{Vc}$ transition region and classified by the response to $\mathrm{CO}_{2}$ stimulation. Type I units were characterized by a late excitatory phase alone, whereas type II units displayed an initial inhibitory phase (asterisk) followed by a late excitatory phase.

$(n=42)$ and subsequently tested for responsiveness to wetting and drying of the ocular surface. All units included in these analyses were responsive to mechanical (brush) and chemical (80\% $\mathrm{CO}_{2}$ ) stimulation of the cornea. Units were classified by the response to $\mathrm{CO}_{2}$ pulses and cutaneous RF properties (Table 1) as described in detail previously (Meng et al., 1997; Hirata et al., 1999) (Fig. 5). Units with a type I-like pattern were found at the $\mathrm{Vi} / \mathrm{Vc}$ transition and $\mathrm{Vc} / \mathrm{C} 1$ junction regions, whereas units with a type II response pattern to $\mathrm{CO}_{2}$ were found only at the $\mathrm{Vi} / \mathrm{Vc}$ transition region. The majority of type II units also had a convergent inhibitory cutaneous RF (see Fig. $8 \mathrm{~A}$; listed as complex units in Table 1). Mechanical stimulation of facial skin or the nasal cavity, or both, inhibited 22 of 25 type II units and none were excited, whereas 5 of 18 type I units were inhibited and 13 were excited. A total of $36 \mathrm{Vi} / \mathrm{Vc}$ units had an inhibitory cutaneous RF (type $\mathrm{I}=8$; type $\mathrm{II}=28$ ). The average inhibitory cutaneous $\mathrm{RF}$ area for all complex units was $2.98 \pm 0.29 \mathrm{~cm}^{2}$ (mean $\pm \mathrm{SE} ; n=$ 34) and was similar for type I and type II complex units. Two additional type II units had a cutaneous inhibitory RF that included the entire body surface. The recording sites for type I ( $n=$ $17)$ and type II $(n=18)$ units that were marked electrolytically and could be verified histologically at the rostral Vi/Vc transition region are shown Figure 6. The recording depth was similar for type I and type II units at the $\mathrm{Vi} / \mathrm{Vc}$ transition region $(2.04 \pm 0.09$ vs $2.05 \pm 0.04 \mathrm{~mm}$ ); however, $\chi^{2}$ analysis indicated that type II units were located more rostrally than type I units $\left(\chi^{2}=5.04\right.$; $\mathrm{df}=1 ; p<0.05)$. Corneal units recorded in laminas I-II at the
O Type I (17)

- Type II (18)

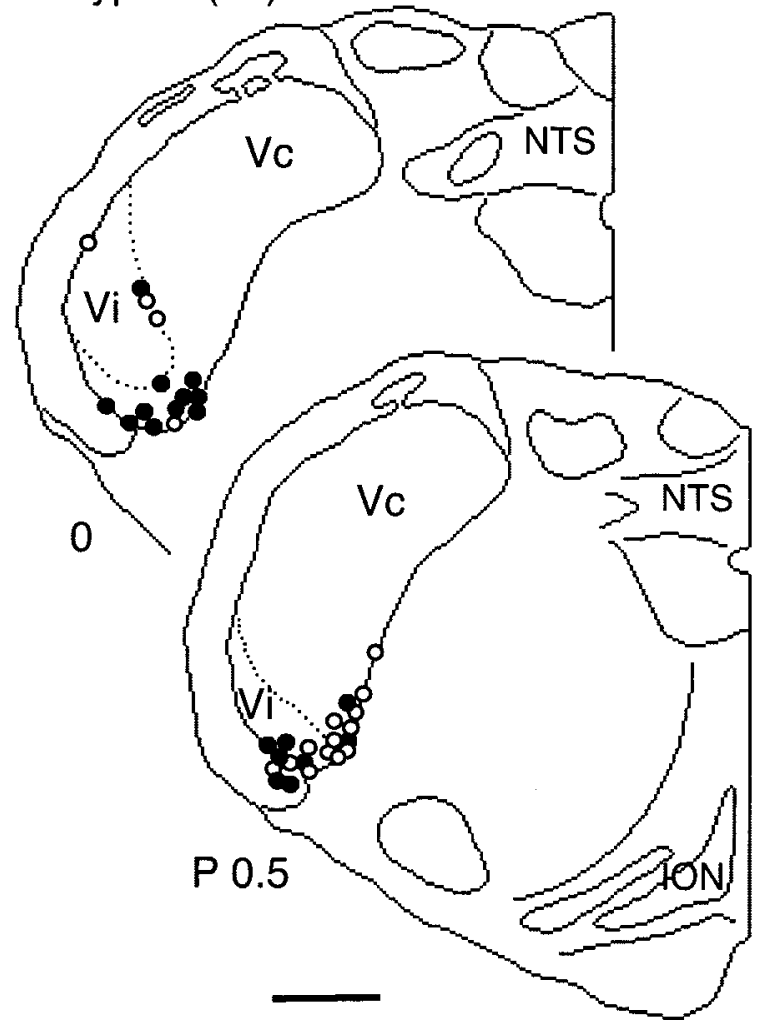

Figure 6. Recording sites at the rostral Vi/Vc transition region for type I and type II units. Type I and type II units were segregated rostrocaudally, with type I units being more likely found at more caudal levels. ION, Inferior olive; NTS, nucleus tractus solitarius; Vc, trigeminal subnucleus caudalis; Vi, trigeminal subnucleus interpolaris. Numbers to bottom left of each outline refer to the distance in millimeters caudal to the obex. Scale bar, $0.5 \mathrm{~mm}$.

caudal $\mathrm{Vc} / \mathrm{C} 1$ junction region displayed only a type I-like response to $80 \% \mathrm{CO}_{2}$, and with one exception, all $\mathrm{Vc} / \mathrm{C} 1$ units received excitatory convergent input from ipsilateral periorbital skin and were classified as WDR- or NS-like units. Each of the 11 $\mathrm{Vc} / \mathrm{C} 1$ units recorded in laminas I-II was excited by mechanical stimulation of the ipsilateral nasal cavity.

Effects of wetting and drying the ocular surface on unit activity Spontaneous activity was monitored continuously for $5 \mathrm{~min}$ before and $10 \mathrm{~min}$ after application of artificial tears to the ocular surface. At $10 \mathrm{~min}$ after wetting of the surface, all excess fluid was gently removed with a tissue paper by the ventrolateral corner of the eye, and unit activity was averaged for the next $1 \mathrm{~min}$. The average firing rate before and after wetting and drying of the ocular surface for the three main classes of cells (defined by the response to $80 \% \mathrm{CO}_{2}$ pulses and recording location) are shown in Figure 7. All units were spontaneously active before wetting of the ocular surface. At the Vi/Vc transition, type II units had a slightly higher average firing rate $(21.1 \pm 4.1$ spikes/sec $)$ than type I units (17.4 \pm 2.2 spikes/sec); however, this difference was not significant. By 1 min after wetting of the cornea, type II units displayed a marked and persistent decrease in firing rate $(>75 \%$ from background; $p<0.01$ ), whereas type I units at the $\mathrm{Vi} / \mathrm{Vc}$ transition or those in laminas I-II at the $\mathrm{Vc} / \mathrm{C} 1$ junction region were not affected consistently. In addition, several $(n=4)$ corneal units were recorded from deep laminas at the $\mathrm{Vc} / \mathrm{Cl}$ junction (depth $>600$ 


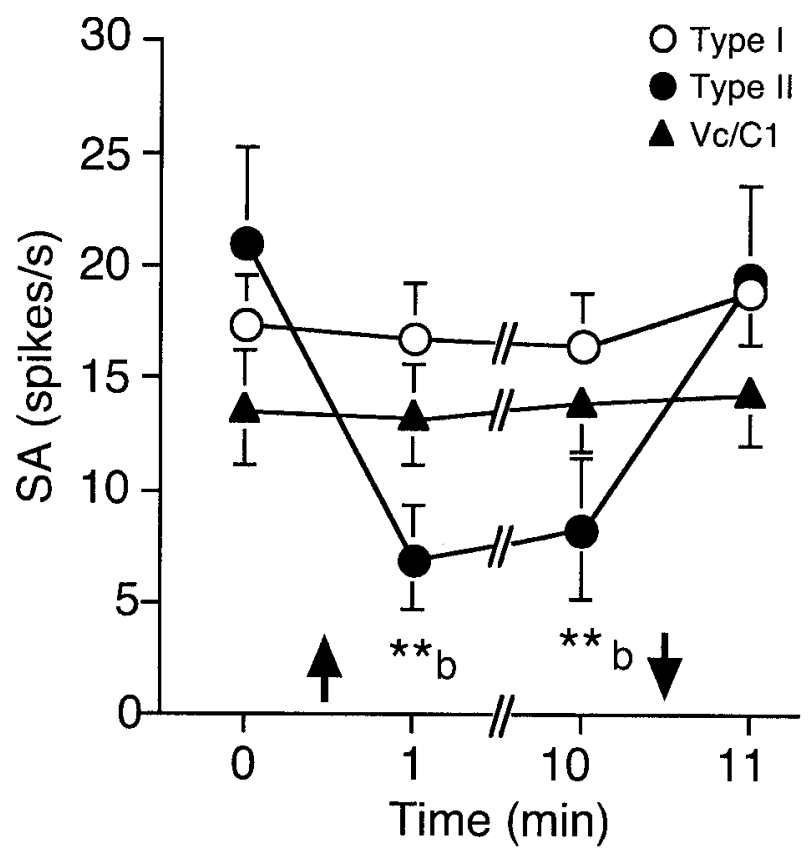

Figure 7. Artificial tears applied to the corneal surface (upward arrow) caused a significant decrease in spontaneous activity of corneal type Il units, whereas acute removal of tears (downward arrow) caused an increase in activity toward resting levels. Type I units recorded at the $\mathrm{Vi} / \mathrm{Vctransition}$ or caudal units found at the $\mathrm{Vc} / \mathrm{C} 1$ junction region displayed only minor changes in spontaneous activity after wetting of the ocular surface. Sample sizes: Vi/Vc units type I $(n=$ 38), Vi/Vcunits type II $(n=31)$, and Vc/C1 $(n=42) .{ }^{* *} p<0.01$ versus pre-wet condition; $b=$ $p<0.01$ versus other cell classes.

$\mu \mathrm{m})$, and none were affected by wetting of the ocular surface (11.7 \pm 5.6 vs $12.4 \pm 6.2$ spikes/sec, before vs after wetting). Drying of the ocular surface caused a prompt increase in activity of type II units to levels similar to the pre-wet condition. Moisture sensitivity among type II units was a highly consistent finding because 30 of 31 units were inhibited by wetting of the cornea (Table 1). The thermal sensitivity of type II units was not studied systematically; however, in a few cases $(n=3)$, the artificial tear fluid was warmed to $40^{\circ} \mathrm{C}$ and found to have a similar inhibitory effect as tear fluid applied at $25^{\circ} \mathrm{C}$. Regression analyses indicated that the magnitude of inhibition after wetting of the ocular surface was proportional to the magnitude of the initial inhibitory phase to $80 \% \mathrm{CO}_{2}$ pulses (Fig. $8 \mathrm{~B}$ ). An example of a type II unit with a complex inhibitory cutaneous RF displaying an initial inhibitory phase to $80 \% \mathrm{CO}_{2}$ pulses and a marked persistent inhibition to wetting of the ocular surface is shown in Figure $8 \mathrm{~A}$. Correlation by Spearman rank-order analyses revealed no significant relationship between the area of the inhibitory cutaneous $\mathrm{RF}$ and the magnitude of inhibition evoked by wetting the cornea or the initial inhibitory phase to $80 \% \mathrm{CO}_{2}$ pulses $(r<0.1 ; n=28)$.

Several units $(n=13)$ were tested for efferent projections to the $\mathrm{SSN}$ region. All $\mathrm{CO}_{2}$-responsive corneal units recorded at the $\mathrm{Vi} / \mathrm{Vc}$ transition (type I, two of two; type II, four of four) were antidromically activated, whereas only three of eight units in laminas I-II at the Vc/C1 junction were driven by sites in the SSN region. The locations of effective antidromic activation sites in SSN were similar to those reported previously (Hirata et al., 2000) (Fig. 7, plane -10.8).

\section{C-fos immunocytochemistry}

Fos-LI was used to determine whether acute drying of the ocular surface caused widespread neural activation in the Vsp, especially in regions outside the $\mathrm{Vi} / \mathrm{Vc}$ transition and $\mathrm{Vc} / \mathrm{C} 1$ junction. The upper and lower eyelids of the left eye were held open for $2 \mathrm{hr}$, and spontaneous tears were gently removed by tissue paper every few minutes. The greatest number of Fos-positive neurons was produced at the level of the ventral $\mathrm{Vi} / \mathrm{Vc}$ transition region ipsilateral to drying, although a small number of cells were found in the corresponding contralateral region (Fig. 9). No Fos-positive cells were found within the $\mathrm{Vsp}$ rostral to the $\mathrm{Vi} / \mathrm{Vc}$ transition region. Fos-LI produced at the $\mathrm{Vi} / \mathrm{Vc}$ transition was restricted to the ventrolateral pole (Fig. $10 \mathrm{~A}$ ), whereas at the caudal $\mathrm{Vc} / \mathrm{Cl}$ junction region a small, but significant, increase in Fos-positive neurons was seen in the superficial laminas ipsilateral to drying (Fig. $10 B)$.

\section{Discussion}

The main finding of this study was the identification of a class of corneal neurons found only at the $\mathrm{Vi} / \mathrm{Vc}$ transition region that responded to acute changes in the moisture status of the ocular surface. Moisture-sensitive Vi/Vc neurons also encoded the intensity of $\mathrm{CO}_{2}$ stimulation of the ocular surface, were excited by mechanical as well as chemical stimuli, and displayed significant levels of background activity, properties shared with other corneal units at the rostral $\mathrm{Vi} / \mathrm{Vc}$ transition and caudal $\mathrm{Vc} / \mathrm{C} 1$ junction regions. Unlike other classes of corneal units, however, moisture-sensitive $\mathrm{Vi} / \mathrm{Vc}$ units displayed a rapid and persistent inhibition to application of artificial tears and excitation to drying of the ocular surface. Nearly all moisture-sensitive units displayed a transient initial inhibitory phase to $\mathrm{CO}_{2}$ pulses (type II units), received convergent inhibitory input from periorbital skin (complex units), and were activated antidromically from the SSN region. The location and properties of moisture-sensitive neurons were consistent with the hypothesis that the $\mathrm{Vi} / \mathrm{Vc}$ transition region is the first site for synaptic integration of peripheral signals necessary for maintaining fluid homeostasis of the ocular surface, whereas more caudal portions of Vc play only a minor role in spontaneous and reflex lacrimation.

The evidence suggested that the properties of $\mathrm{Vi} / \mathrm{Vc}$ neurons classified as moisture-sensitive derive from central processing rather than selective input from unique types of primary afferents. First, although it is possible that a specialized class of moisture-sensing primary afferent neuron exists, support for such cells has not been reported. Studies using in situ approaches report that corneal afferents maintain a low level of spontaneous activity provided the ocular surface is kept moist and not damaged (Lele and Weddell, 1959; Belmonte and Giraldez, 1981; Belmonte and Gallar, 1996), whereas moisture-sensitive Vi/Vc units often fall silent after artificial tears are applied. Second, the central projections of corneal afferents are not segregated by modality within the trigeminal brainstem complex, because second-order neurons responsive to noxious mechanical, chemical, or thermal stimuli are found at both the rostral Vi/Vc transition and caudal Vc/C1 junction regions (Meng et al., 1997; Hirata et al., 2003). Assuming that both regions receive common signals from the ocular surface, then moisture-sensitive neurons should be found in both the $\mathrm{Vi} / \mathrm{Vc}$ and $\mathrm{Vc} / \mathrm{C} 1$ regions; however, only $\mathrm{Vi} / \mathrm{Vc}$ units displayed consistent responses to acute changes in the moisture status of the ocular surface. Third, nearly all Vi/Vc units with moisture sensitivity (30 of 33) displayed an initial inhibitory phase followed by excitation to pulses of $\mathrm{CO}_{2}$, and the majority of these units also received inhibitory input from periorbital facial skin and nasal cavity. These properties suggested that moisturesensitive Vi/Vc units were subject to strong local GABAergic controls. Lu and Perl (2003) report that the spinal substantia gelati- 
nosa, a major termination area for smalldiameter sensory afferents, consisted of functional modules in which pairs of neurons were linked by local GABAergic interneurons and that the presynaptic and postsynaptic neurons of the module received direct C-fiber input. Such an arrangement was consistent with the present results in which type II units were initially inhibited by $\mathrm{CO}_{2}$ pulses and excited after a delay. A circuit in which GABAergic interneurons are activated at lower concentrations of $\mathrm{CO}_{2}$ than required for excitation would explain the response pattern of type II neurons (Fig. 11). The nature of the afferent input responsible for the high rate of spontaneous activity of type II cells was not explored in this study; however, one possible source of input may be the caudal $\mathrm{Vc} / \mathrm{C} 1$ region via intersubnuclear connections, because local blockade of this region by $\mathrm{CoCl}_{2}$ increased the spontaneous activity of corneal units at the $\mathrm{Vi} / \mathrm{Vc}$ transition [Hirata et al. (2003), their Fig. 4]. Evidence for $\mathrm{GABA}_{\mathrm{A}}$ receptor-mediated control of $\mathrm{Vi} / \mathrm{Vc}$ units was strengthened by recent findings that local muscimol inhibited all Vi/Vc corneal units tested in a BMI-reversible manner (Hirata et al., 2003). GABAergic neurons (Matthews et al., 1988; Ginestal and Matute, 1993; Polgar and Antal, 1995; Wang et al., 2000) and $\mathrm{GABA}_{\mathrm{A}}$ receptors (Fritschy and Mohler, 1995; Kondo et al., 1995) are found throughout the trigeminal brainstem complex, including at the $\mathrm{Vi} / \mathrm{Vc}$ transition and $\mathrm{Vc} / \mathrm{C} 1$ junction regions. In addition, the results suggested that the nature of the convergent input and local GABAergic control of rostral $\mathrm{Vi} / \mathrm{Vc}$ and caudal $\mathrm{Vc} / \mathrm{C} 1$ corneal units was quite different. Although all type II Vi/Vc units receiving convergent nasal input were inhibited by nasal stimulation, all caudal $\mathrm{Vc} / \mathrm{Cl}$ corneal units with nasal input were excited. Although not tested in this study, it is possible that $\mathrm{GABA}_{\mathrm{B}}$ receptor-mediated mechanisms also contribute to control of ocular homeostasis, because baclofen injection into the $\mathrm{Vi} / \mathrm{Vc}$ transition partially reduced the magnitude of blink reflexes (Pellegrini et al., 1995). Fourth, the magnitude of inhibition to wetting of the ocular surface was proportional to the initial inhibitory phase to $\mathrm{CO}_{2}$ pulses for type II units, suggesting that resting and nociceptor-evoked tear production are mediated though common mechanisms. A common mechanism would be predicted because psychophysical studies indicate that drying or acidic stimulation of the ocular surface is perceived as irritating or painful in awake humans if presented for more than a brief period (Acosta et al., 2001).

Several features of the $\mathrm{Vi} / \mathrm{Vc}$ transition suggest a role in specialized aspects of trigeminal function, especially concerning structures innervated by the ophthalmic branch of the trigeminal nerve. The $\mathrm{Vi} / \mathrm{Vc}$ transition may serve as a common pathway for reflex lacrimation caused by ocular stimulation, cluster headache (Goadsby, 2002), and nasal irritation (Drummond, 1995). Local anesthesia of either the ocular surface or nasal cavity (Gupta et al., 1997) reduced aqueous tear production. A high percentage of type II Vi/Vc units (22 of 25 tested) received convergent inputs from the ocular surface and nasal muscosa (this study), whereas nearly all $\mathrm{Vi} / \mathrm{Vc}$ units driven by dural membrane stimulation were driven by corneal input (Schepelmann et al., 1999). The $\mathrm{Vi} / \mathrm{Vc}$ transition has been implicated in the control of eye-blink reflexes (Pellegrini et al., 1995; Zerari-Mailly et al., 2003), and this

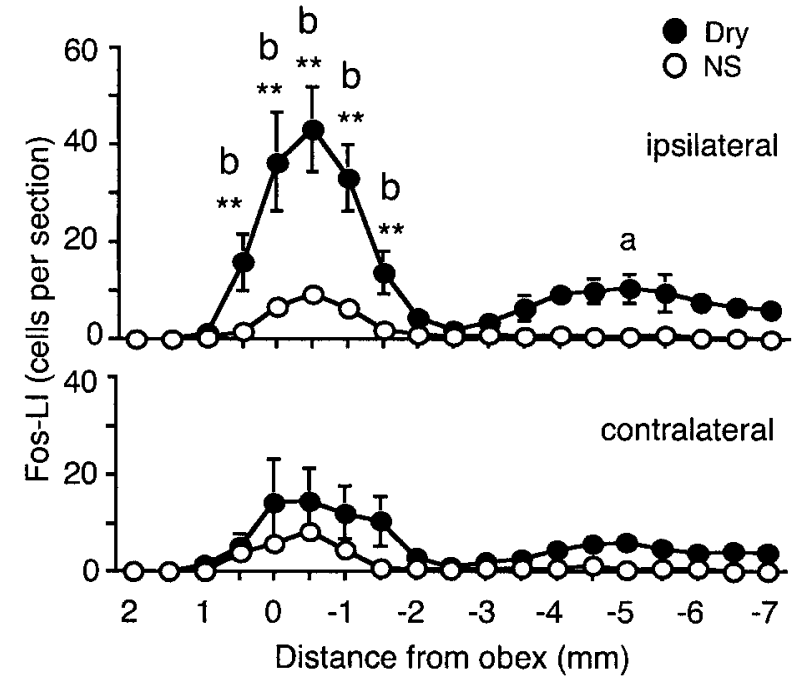

Figure 9. Rostrocaudal distribution of Fos-positive neurons within the Vsp ipsilateral and contralateral to drying of the ocular surface. The upper and lower eyelids of the left eye were gently retracted by adhesive strips, and tears were removed throughout the $2 \mathrm{hr}$ survival period (Dry). The no-stimulus controls (NS) also were anesthetized and survived for $2 \mathrm{hr}$; however, eyelids were allowed to close naturally and tears were allowed to accumulate. ${ }^{* *} p<0.01$, ipsilateral versus contralateral; $\mathrm{a}=p<0.05, \mathrm{~b}=p<0.01$ versus NS controls; $n=4$ per treatment.

may be one function for type I corneal units that projected to the $\mathrm{SSN}-$ facial motor nucleus region but were not moisture sensitive (Hirata et al., 2000; this study). The present study did not allow for more precise functional definition of type I and type II units; however, the slow initial pause of type II units suggests a role in long-term drive to the lacrimation circuit rather than rapid coordination with eye blinks and tear film spreading (Tsubota, 1998). The Vi/Vc transition also may be involved in the control of intraocular pressure, because topical application of cannabinoid agonists to the ocular surface reduced neural activity at the Vi/Vc transition but not at the $\mathrm{Vc} / \mathrm{C} 1$ junction region (Bereiter et al., 2002). Convergence of ocular, nasal, and dural input to the ventral Vi/Vc transition is consistent with the expected somatotopic representation of ophthalmic structures in the Vsp (Panneton 

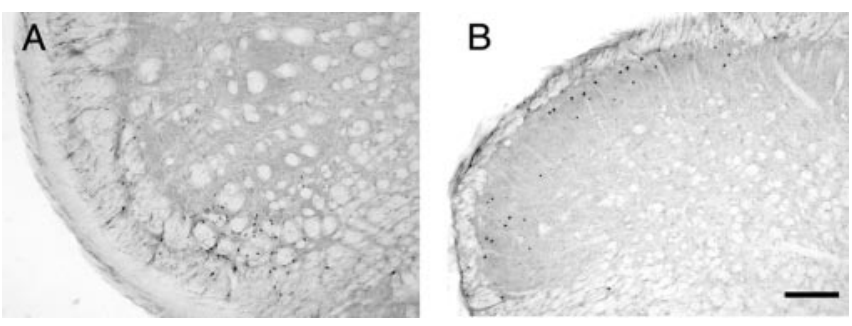

Figure 10. Examples of Fos-positive neuronal nuclei at the Vi/Vctransition $(A)$ and caudal $\mathrm{VC} / \mathrm{C} 1$ junction $(B)$ regions ipsilateral to the dry ocular surface. Note that Fos-LI was restricted to the ventrolateral portion of the $\mathrm{Vi} / \mathrm{Vc}$ transition and to the superficial laminas at the $\mathrm{Vc} / \mathrm{C} 1$ junction region. Scale bar, $0.2 \mathrm{~mm}$.

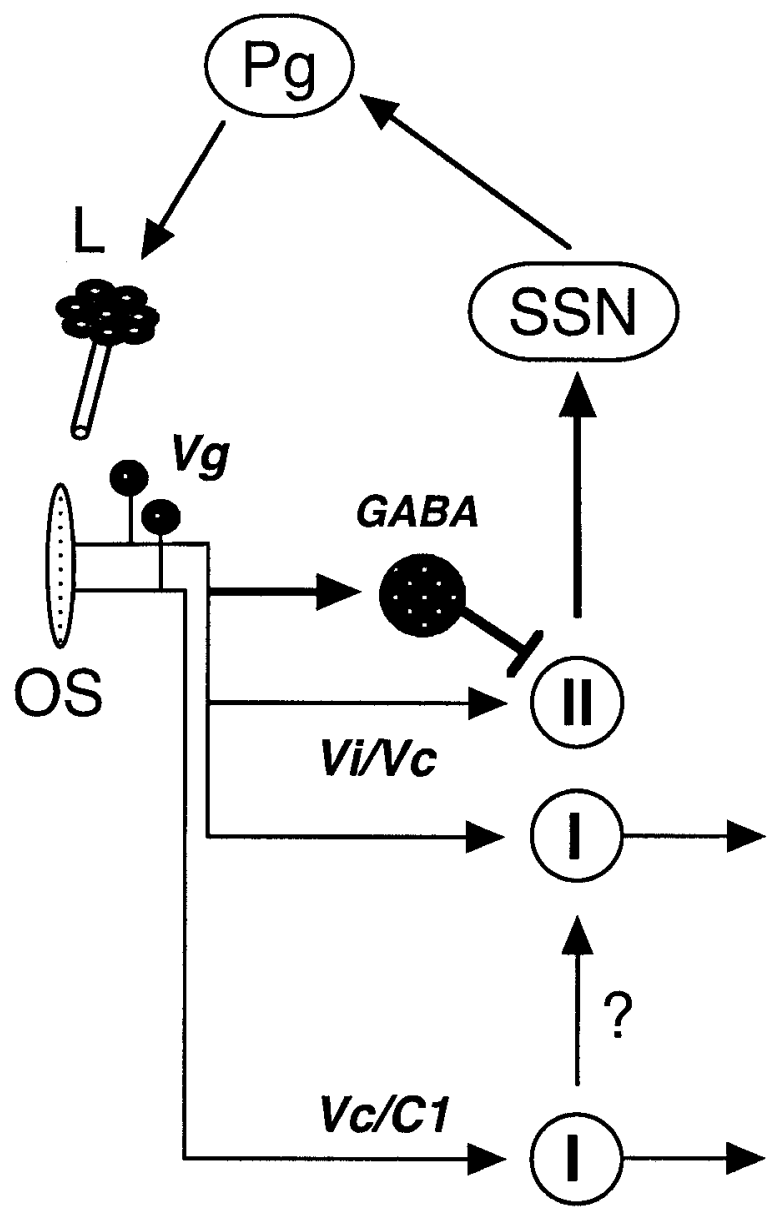

Figure 11. Summary diagram indicating possible relationships between corneal units at the $\mathrm{Vi} / \mathrm{Vc}$ transition and $\mathrm{Vc} / \mathrm{C} 1$ junction regions. Note that type II units, found only at the $\mathrm{Vi} / \mathrm{Vc}$ transition, reliably responded to changes in moisture status of the ocular surface. GABAergic interneurons $(-$ are proposed to play a prominent role, because nearly all type II units displayed an initial inhibitory phase to $\mathrm{CO}_{2}$ stimulation and a convergent $\mathrm{RF}$ from facial skin, results that cannot be explained by peripheral mechanisms. I, Type I unit; II, type II unit; L, lacrima gland; OS, ocular surface; $\mathrm{Pg}$, pterygopalatine ganglion; $\mathrm{SSN}$, superior salivatory nucleus; $\mathrm{Vg}$, trigeminal ganglion. A thick arrow indicates a strong connection between type II units at the $\mathrm{Vi} / \mathrm{Vc}$ transition region and preganglionic neurons in the SSN. The role of intersubnuclear communication between the Vi/Vctransition and Vc/C1 junction regions (Hirata et al., 2003) in modifying reflex tear formation remains to be assessed.

and Burton, 1981; Marfurt and del Toro, 1987; Anton and Peppel, 1991; Takemura et al., 1991; Lu et al., 1993; Strassman and Vos, 1993; Strassman et al., 1994; Meng and Bereiter, 1996; Gong et al., 2003). Noxious sensory input from other trigeminal structures such as the temporomandibular joint (Hathaway et al.,
1995) and masseter muscle (Ikeda et al., 2003), however, also activates neurons at the ventral $\mathrm{Vi} / \mathrm{Vc}$ transition, suggesting a broader role in trigeminal nociception. At least in rodents, the ventral $\mathrm{Vi} / \mathrm{Vc}$ transition is the main source of trigeminal projections to the nucleus submedius, a medial thalamic relay thought to contribute to the affective aspects of pain (Yoshida et al., 1991; Ikeda et al., 2003).

Corneal units in laminas $\mathrm{I}-\mathrm{II}$ at the $\mathrm{Vc} / \mathrm{C} 1$ junction may contribute to the discriminative aspects of ocular pain because morphine inhibited all cells in this region, whereas $>30 \%$ of corneal units at the $\mathrm{Vi} / \mathrm{Vc}$ transition were excited (Meng et al., 1998; Hirata et al., 2000). The present study provided little evidence that corneal units at the $\mathrm{Vc} / \mathrm{Cl}$ junction region were moisture sensitive and thus might have contributed to the maintenance of fluid homeostasis of the ocular surface. This finding was somewhat unexpected because others have proposed that trigeminal and spinal lamina I neurons monitor signals critical for general homeostasis (Craig, 1996). It is possible that lamina I units serve other aspects of ocular homeostasis, not assessed in this study, such as reflex control of blood flow to the eye or lacrimal glands (Yasui et al., 1997). Indeed, drying of the ocular surface over a 2 hr period produced a small but significant increase in the number of Fos-positive neurons in laminas I-II ipsilateral to the side of drying.

The present study is the first report of a class of central neurons located uniquely at the $\mathrm{Vi} / \mathrm{Vc}$ transition region that are sensitive to the moisture status of the ocular surface and likely to be critical for reflex tear production. Several chronic conditions affect tear production, yet little is known regarding possible central mechanisms in these disorders. For example, dry eye caused by either reduced tear volume (Sjogren's syndrome) or elevated tear osmolarity (meibomian gland dysfunction) leads to increased friction on the cornea surface during eye blinks (Gilbard, 1999). Management of dry eye by topical treatment often is unsatisfactory and has led to the proposal that long-term changes in central brain circuits, attributable to persistent subclinical inflammation, may contribute to the irritation in dry eye (Van Bijsterveld et al., 2003). Indeed, in preliminary studies, acute inflammation of facial skin reduced the moisture sensitivity of $\mathrm{Vi} / \mathrm{Vc}$ type II units (our unpublished observations). Also, because tear composition as well as volume are critical factors in ocular homeostasis (Pflugfelder et al., 2000; Dartt, 2002), it remains to be determined whether gland-specific (e.g., lacrimal, meibomian) second-order neurons exist at the $\mathrm{Vi} / \mathrm{Vc}$ transition region that selectively control the different biochemical constituents of tear fluid.

\section{References}

Acosta MC, Belmonte C, Gallar J (2001) Sensory experiences in humans and single-unit activity in cats evoked by polymodal stimulation of the cornea. J Physiol (Lond) 534:511-525.

Anton F, Peppel P (1991) Central projections of trigeminal primary afferents innervating the nasal mucosa: a horseradish peroxidase study in the rat. Neuroscience 41:617-628.

Belmonte C, Gallar J (1996) Corneal nociceptors. In: Neurobiology of nociceptors (Belmonte C, Cervero F, eds), pp 146-183. New York: Oxford UP.

Belmonte C, Giraldez F (1981) Responses of cat corneal sensory receptors to mechanical and thermal stimulation. J Physiol (Lond) 321:355-368.

Bereiter DA, Hirata H, Hu JW (2000) Trigeminal subnucleus caudalis: beyond homologies with the spinal dorsal horn. Pain 88:221-224.

Bereiter DA, Bereiter DF, Hirata H (2002) Topical cannabinoid agonist, WIN55,212-2, reduces cornea-evoked trigeminal brainstem activity in the rat. Pain 99:547-556.

Craig AD (1996) An ascending general homeostatic afferent pathway originating in lamina I. Prog Brain Res 107:225-242. 
Dartt DA (2002) Regulation of mucin and fluid secretion by conjunctival epithelial cells. Prog Retin Eye Res 21:555-576.

Drummond PD (1995) Lacrimation and cutaneous vasodilatation in the face induced by painful stimulation of the nasal ala and upper lip. J Auton Nerv Syst 51:109-116.

Dubner R, Bennett GJ (1983) Spinal and trigeminal mechanisms of nociception. Annu Rev Neurosci 6:381-418.

Fritschy J-M, Mohler H (1995) GABA $_{\mathrm{A}}$-receptor heterogeneity in the adult rat brain: differential regional and cellular distribution of seven major subunits. J Comp Neurol 359:154-194.

Gilbard JP (1999) Dry eye, blepharitis and chronic eye irritation: divide and conquer. J Ophthalmic Nurs Technol 18:109-115.

Ginestal E, Matute C (1993) Gamma-aminobutyric acid-immunoreactive neurons in the rat trigeminal nuclei. Histochemistry 99:49-55.

Goadsby PJ (2002) Pathophysiology of cluster headache: a trigeminal autonomic cephalgia. Lancet Neurol 1:251-257.

Gong S, Zhou Q, LeDoux MS (2003) Blink-related sensorimotor anatomy in the rat. Anat Embryol 207:193-208.

Gupta A, Heigle T, Pflugfelder SC (1997) Nasolacrimal stimulation of aqueous tear production. Cornea 16:645-648.

Hathaway CB, Hu JW, Bereiter DA (1995) Distribution of Fos-like immunoreactivity in the caudal brainstem of the rat following noxious chemical stimulation of the temporomandibular joint. J Comp Neurol 356:444-456

Hirata H, Hu JW, Bereiter DA (1999) Responses of medullary dorsal horn neurons to corneal stimulation by $\mathrm{CO}_{2}$ pulses: intensity encoding, effects of morphine, and thalamic projections in the rat. J Neurophysiol 82:2092-2107.

Hirata H, Takeshita S, Hu JW, Bereiter DA (2000) Cornea-responsive medullary dorsal horn neurons: modulation by local opioid agonists and projections to thalamus and brainstem. J Neurophysiol 84:1050-1061.

Hirata H, Okamoto K, Bereiter DA (2003) GABA receptor activation modulates corneal unit activity in rostral and caudal portions of trigeminal subnucleus caudalis. J Neurophysiol 90:2837-2849.

Hu JW (1990) Response properties of nociceptive and non-nociceptive neurons in the rat's trigeminal subnucleus caudalis (medullary dorsal horn) related to cutaneous and deep craniofacial afferent stimulation and modulation by diffuse noxious inhibitory controls. Pain 41:331-345.

Ikeda T, Terayama R, Jue S, Sugiyo S, Dubner R, Ren K (2003) Differential rostral projections of caudal brainstem neurons receiving trigeminal input after masseter inflammation. J Comp Neurol 465:220-233.

Kondo E, Kiyama H, Yamano M, Shida T, Ueda Y, Tohyama M (1995) Expression of glutamate (AMPA) and gamma-aminobutyric acid (GABA)A receptors in the rat caudal trigeminal spinal nucleus. Neurosci Lett 186:169-172.

Lele PP, Weddell G (1959) Sensory nerves of the cornea and cutaneous sensibility. Exp Neurol 1:334-359.

Lipski J (1981) Antidromic activation of neurones as an analytic tool in the study of the central nervous system. J Neurosci Methods 4:1-32.

Lu J, Hathaway CB, Bereiter DA (1993) Adrenalectomy enhances Fos-like immunoreactivity within the spinal trigeminal nucleus induced by noxious thermal stimulation of the cornea. Neuroscience 54:809-818.

Lu Y, Perl ER (2003) A specific inhibitory pathway between substantia gelatinosa neurons receiving direct C-fiber input. J Neurosci 23:8752-8758.

Marfurt CF (1981) The central projections of trigeminal primary afferent neurons in the cat as determined by the transganglionic transport of horseradish peroxidase. J Comp Neurol 203:785-798.

Marfurt CF, del Toro DR (1987) Corneal sensory pathway in the rat: a horseradish peroxidase tracing study. J Comp Neurol 261:450-459.

Marfurt CF, Kingsley RE, Echtenkamp E (1989) Sensory and sympathetic innervation of the mammalian cornea. Invest Ophthalmol Visual Sci 30:461-472.

Mathers WD (2000) Why the eye becomes dry: a cornea and lacrimal gland feedback model. CLAO J 26:159-165.

Matthews MA, McDonald GK, Hernandez TV (1988) GABA distribution in a pain-modulating zone of trigeminal subnucleus interpolaris. Somatosens Motor Res 5:205-217.

Meng ID, Bereiter DA (1996) Differential distribution of Fos-like immunoreactivity in the spinal trigeminal nucleus after noxious and innocuous thermal and chemical stimulation of rat cornea. Neuroscience 72:243-254.

Meng ID, Hu JW, Benetti AP, Bereiter DA (1997) Encoding of corneal input in two distinct regions of the spinal trigeminal nucleus in the rat: cutaneous receptive field properties, responses to thermal and chemical stimulation, modulation by diffuse noxious inhibitory controls, and projections to the parabrachial area. J Neurophysiol 77:43-56.

Meng ID, Hu JW, Bereiter DA (1998) Differential effects of morphine on corneal-responsive neurons in rostral versus caudal regions of spinal trigeminal nucleus in the rat. J Neurophysiol 79:2593-2602.

Panneton WM, Burton H (1981) Corneal and periocular representation within the trigeminal sensory complex in the cat studied with transganglionic transport of horseradish peroxidase. J Comp Neurol 199:327-344.

Paxinos G, Watson C (1997) The rat brain in stereotaxic coordinates. New York: Academic.

Pellegrini JJ, Horn AKE, Evinger C (1995) The trigeminally evoked blink reflex. I. Neuronal circuits. Exp Brain Res 107:166-180.

Pflugfelder SC, Solomon A, Stern ME (2000) The diagnosis and management of dry eye. A twenty-five year review. Cornea 19:644-649.

Polgar E, Antal M (1995) The colocalization of parvalbumin and calbindinD28k with GABA in the subnucleus caudalis of the rat spinal trigeminal nucleus. Exp Brain Res 103:402-408.

Renehan WE, Jacquin MF (1993) Anatomy of central nervous system pathways related to head pain. In: The headaches (Olesen J, Tfelt-Hansen P, Welch K, eds), pp 59-68. New York: Raven.

Schepelmann K, Ebersberger A, Pawlak M, Oppmann M, Messlinger K (1999) Response properties of trigeminal brain stem neurons with input from dura mater encephali in the rat. Neuroscience 90:543-554.

Sessle BJ (2000) Acute and chronic craniofacial pain: brainstem mechanisms of nociceptive transmission and neuroplasticity, and their clinical correlates. Crit Rev Oral Biol Med 11:57-91.

Stern ME, Beuerman RW, Fox RI, Gao J, Mircheff AK, Pflugfelder SC (1998) The pathology of dry eye: the interaction between the ocular surface and lacrimal glands. Cornea 17:584-589.

Strassman AM, Vos BP (1993) Somatotopic and laminar organization of Fos-like immunoreactivity in the medullary and cervical dorsal horn induced by noxious facial stimulation in the rat. J Comp Neurol 331:495-516.

Strassman AM, Mineta Y, Vos BP (1994) Distribution of Fos-like immunoreactivity in the medullary and upper cervical dorsal horn produced by stimulation of dural blood vessels in the rat. J Neurosci 14:3725-3735.

Takemura M, Sugimoto T, Shigenaga Y (1991) Difference in central projection of primary afferents innervating facial and intraoral structures in the rat. Exp Neurol 111:324-331.

Toth IE, Boldogkoi Z, Medveczky I, Palkovits M (1999) Lacrimal preganglionic neurons form a subdivision of the superior salivatory nucleus of rat: transneuronal labeling by pseudorabies virus. J Auton Nerv Syst 77:45-54.

Tsubota K (1998) Tear dynamics and dry eye. Prog Ret Eye Res 17:565-596.

Van Bijsterveld OP, Kruize AA, Bleys RL (2003) Central nervous system mechanisms in Sjogren's syndrome. Br J Ophthalmol 87:128-130.

Walcott B (1998) The lacrimal gland and its veil of tears. News Physiol Sci 13:97-103.

Wang D, Li YQ, Li JL, Kaneko T, Nomura S, Mizuno N (2000) $\gamma$-aminobutyric acid- and glycine-immunoreactive neurons postsynaptic to substance P-immunoreactive axon terminals in the superficial layers of the rat medullary dorsal horn. Neurosci Lett 288:187-190.

Winer BJ (1971) Statistical principles in experimental design. New York: McGraw-Hill.

Yasui T, Karita K, Izuni H, Tamai M (1997) Correlation between vasodilatation and secretion in the lacrimal gland elicited by stimulation of the cornea and facial nerve root of the cat. Invest Ophthalmol Vis Sci 38:2476-2482.

Yoshida A, Dostrovsky JO, Sessle BJ, Chiang CY (1991) Trigeminal projections to the nucleus submedius of the thalamus in the rat. J Comp Neurol 307:609-625.

Zerari-Mailly F, Dauvergne C, Buisseret P, Buisseret-Delmas C (2003) Localization of trigeminal, spinal, and reticular neurons involved in the rat blink reflex. J Comp Neurol 467:173-184. 